\title{
Stannylcarbonylation of Hydroxy-substituted Alkynes. Intramoleuclar Trapping of $\alpha$-Ketenyl Radicals by a Hydroxy Group Leading to Lactols ${ }^{\dagger}$
}

\author{
Ilhyong Ryu, ${ }^{*}$ Takahide Fukuyama, Osamu Nobuta, and Yoshitaka Uenoyama \\ Department of Chemistry, Graduate School of Science, Osaka Prefecture University, Sakai, Osaka 599-8531 \\ *E-mail: ryu@c.s.osakafu-u.ac.jp \\ Received November 16, 2009, Accepted February 15, 2010
}

Key Words: Radical carbonylation, $\alpha$-Ketenyl radicals, Lactols, Carbon monoxide, Tin radical

Radical carbonylation reactions are becoming a powerful tool for the introduction of carbon monoxide into organic molecules. ${ }^{1}$ We have previously reported that free-radical mediated stannylcarbonylation of alkynes provides a useful entry to $\alpha, \beta-$ unsaturated acyl radicals, which are likely to exist in an equilibrium with $\alpha$-ketenyl radicals. ${ }^{2,3}$ Intra- and intermolecular trapping attempts of $\alpha, \beta$-unsaturated acyl radicals $/ \alpha$-ketenyl radicals led us to postulate that ketenyl carbonyl has an electrophilic nature sufficient enough to allow for the attack of nitrogen nucleophiles, such as imines, oxazolines, and amines. ${ }^{4}$ While stannylcarbonylation of amino-substituted alkynes gave lactams, we were curious at knowing if the stannylcarbonylation of hydroxy-substituted alkynes would give the corresponding lactones or not, since nucleophilicity of alcohols is not so strong as that of amines. We report herein the results of the free-radical mediated stannylcarbonylation reaction of 5-hydroxyalkynes, which gave cyclized carbonylated products, lactols, as principal carbonylated products. Interestingly recent work of Nishii, Tanabe, and coworkers reported that lactols can be formed by radical carbonylation of cyclopropyl radicals, through the trapping of intermediary acyl radicals by an internal hydroxyl group. ${ }^{5}$

Choosing 4-pentyn-1-ol (1a), as a model compound, we examined AIBN-initiated stannylcarbonylation reaction. As shown in Scheme 1, the reaction gave cyclized carbonylated products, unsaturated lactone $\mathbf{3 a}$ and lactol $\mathbf{4 a}$, whereas lactone 2a was formed in only a trace amount. The formation of lactol 4a presumably requires two equivalents of tributyltin hydride. In consistent with this, the reaction using 1.3 equiv of tributyltin hydride caused the shortage of tin hydride resulting in the recovery of 1a. With 3.1 equivalents of tin hydride, the yield of $4 \mathbf{a}$ increased up to $46 \%$.

We also examined stannylcarbonylation of 3-butyn-1-ol (1) and 5-hexyn-1-ol (1c). These results are shown in Scheme 2.

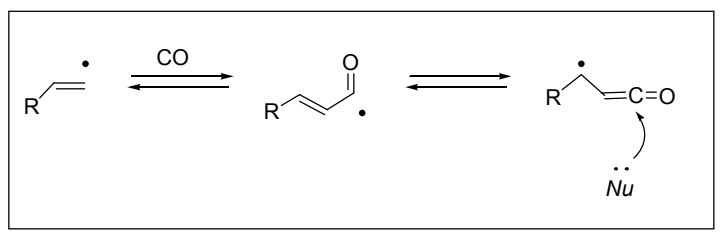

Figure 1. Concept of ketenyl radical trapping

${ }^{\dagger}$ This paper is dedicated to Professor Sunggak Kim on the occasion of his honorable retirement.
In the case of $\mathbf{1 b}$, a mixture of $\alpha$-stannylmethyl lactone $\mathbf{2 b}$, unsaturated lactone $\mathbf{3 b}$, and lactol $\mathbf{4 b}$ was obtained. In the case of 1c, while the formation of $\mathbf{2 c}$ was suppressed as in the case of 1a, the hydroxy aldehyde $\mathbf{4 c}$, a ring-opened form of a sevenmembered ring lactol, was formed.

In Table 1, the results of the synthesis of six-membered ring lactols from 4-alkyn-1-ols, CO, and tributyltin hydride are shown. Similarly as in the case of $\mathbf{4 a}$, lactols $\mathbf{4 d}, \mathbf{4 e}, \mathbf{4 f}$, and $\mathbf{4 g}$ were prepared by the present tin hydride-based radical carbonylation.

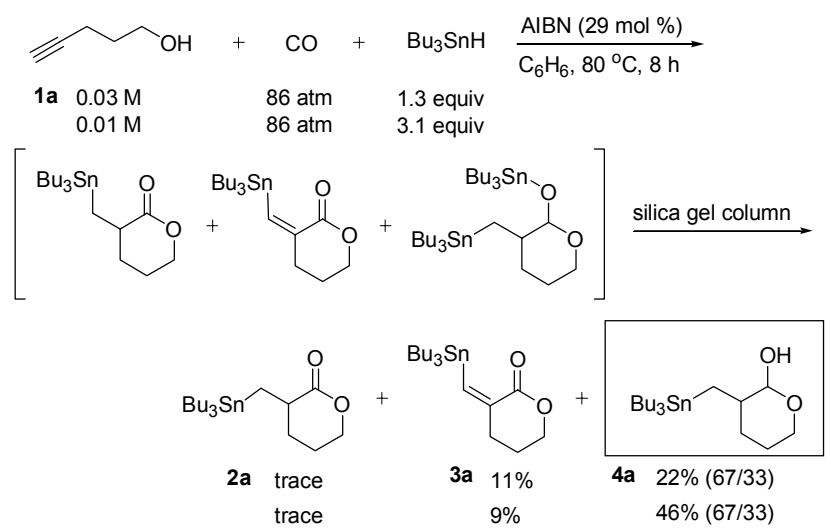

Scheme 1. Stannylcarbonylation of 4-pentyn-1-ol (1a)
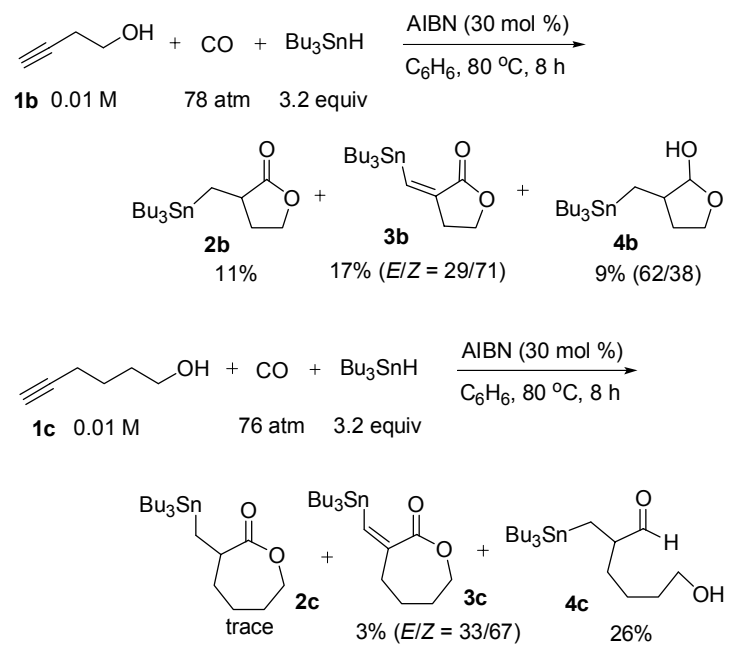

Scheme 2. Stannylcarbonylation of 3-butyn-1-ol (1b) and 5-hexyn$1-\mathrm{ol}(\mathbf{1 c})$ 
Table 1. Synthesis of six-membered lactols 4 from alkynyl alcohols $\mathbf{1}$ and $\mathrm{CO}$ and tributyltin hydride

entry 5-hydroxy alkynes 1

${ }^{a}$ Isolated yields by silica gel column chromatography. ${ }^{b}$ Determined by ${ }^{1} \mathrm{H}$ NMR.

In Scheme 3, we proposed reaction pathways leading to lactones and lactols, having an example of 1a. The first key step may be trapping of an $\alpha$-ketenyl radical by an internal hydroxy group to lead to a hydroxyallyl radical $\mathbf{A}$. Then $\mathbf{A}$ would undergo 1,4-hydrogen shift, which leads to oxyallyl radical B. Probably the successive 1,4-Sn shift from $\mathrm{C}$ to $\mathrm{O}$ would take place to give stannyloxyallyl radical $\mathbf{C}$. Hydrogen abstraction of $\mathbf{C}$ by tributyltin hydride followed by hydrostannylation would give bisstanylated lactol as a precursor for lactol $4 \mathbf{a}^{6}{ }^{6}$ In this reaction, $\mathbf{2 a}$ was formed in only a trace amount. This might suggest that a proposed 1,4-Sn shift from $\mathbf{B}$ to $\mathbf{C}$ is a very rapid process. Our preliminary $\mathrm{MO}$ calculations predict that 1-oxyallyl radicals are thermodynamically more stable than oxaallyl radicals and this is in line with the proposed consecutive isomerization from $\mathbf{A}$ to $\mathbf{C}$ via $\mathbf{B}$.

To our knowledge 1,4-Sn shift from $\mathrm{C}$ to $\mathrm{O}$ has yet to be known, ${ }^{7}$ however, oxygen-philic 1,5-Sn shift have been originally reported by the Kim group in 1991 (Scheme 4). ${ }^{8}$ It is also
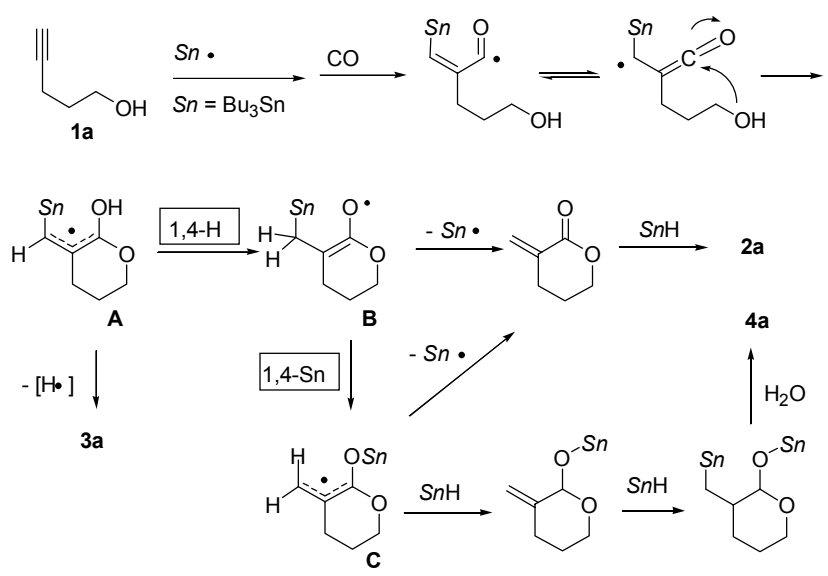

Scheme 3. Proposed mechanisms for lactones and lactols

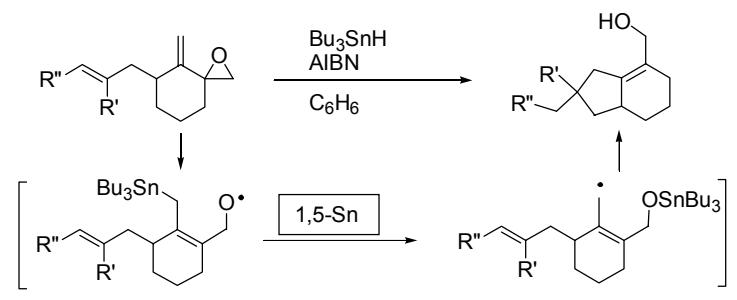

Scheme 4. Kim's 1,5-Sn shift from $\mathrm{C}$ to $\mathrm{O}$

proposed by Tsai and coworkers that 1,3-Sn shift from $\mathrm{C}$ to $\mathrm{O}$ is involved in the cyclohexanol synthesis. ${ }^{9}$

In conclusion, lactols are formed as principal products in the tin-hydride mediated radical carbonylations of hydroxysubstituted alkynes. We propose the reaction pathway involving intramolecular trapping of $\alpha$-ketenyl radicals by a hydroxy group, followed by consecutive 1,4-H and 1,4-Sn shift. Further applications as well as probing the proposed reaction mechanisms are underway in our laboratory.

Acknowledgments. We thank the JSPS for financial support of this work.

\section{References}

1. For reviews on radical carbonylations, see: (a) Ryu, I.; Sonoda, N. Angew. Chem. Int. Ed. Engl. 1996, 35, 1050. (b) Ryu, I.; Sonoda, N.; Curran, D. P. Chem. Rev. 1996, 96, 177. (c) Ryu, I. Chem. Soc. Rev. 2001, 30, 16. Also see a review on acyl radicals: (d) Chatgilialoglu, C.; Crich, D.; Komatsu, M.; Ryu, I. Chem. Rev. 1999, 99, 1991.

2. For a review, see: Ryu, I.; Uenoyama, Y.; Matsubara, H. Bull. Chem. Soc. Jpn. 2006, 79, 1476.

3. Matsubara, H.; Ryu, I.; Schiesser, C. H. J. Org. Chem. 2005, 70, 3610.

4. (a) Ryu, I.; Miyazato, H.; Kuriyama, K.; Matsu, K.; Tojino, M.; Fukuyama, T.; Minakata, S.; Komatsu, M. J. Am. Chem. Soc. 2003, 125, 5632. (b) Tojino, M.; Otsuka, N.; Fukuyama, T.; Matsubara, H.; Schiesser, C. H.; Kuriyama, H.; Miyazato, H.; Minakata, S.; Komatsu, M.; Ryu, I. Org. Biomol. Chem. 2003, 1, 4262. (c) Tojino, M.; Uenoyama, Y.; Fukuyama, T.; Ryu, I. Chem. Commun. 2004, 2482. (d) Uenoyama, Y.; Fukuyama, T.; Nobuta, O.; Matsubara, H.; Ryu, I. Angew. Chem. Int. Ed. 2005, 44, 1075. (e) Tojino, M.; Otsuka, N.; Fukuyama, T.; Matsubara, H.; Ryu, I. J. Am. Chem. Soc. 2006, 128, 7712. (f) Uenoyama, Y.; Fukuyama, T.; Ryu, I. Org. Lett. 2007, 9, 935.

5. Nishii, Y.; Nagano, T.; Gotoh, H.; Nagase, R.; Motoyoshiya, J.; Aoyama, H.; Tanabe, Y. Org. Lett. 2007, 9, 563.

6. For facile reduction of 6-membered lactones using $\mathrm{SmI}_{2}$, see: (a) Duffy, L. A.; Matsubara, H.; Procter, D. J. J. Am. Chem. Soc. 2008, 130, 1136. (b) Parmar, D.; Duffy, L. A.; Sadasivam, D. V.; Matsubara, H.; Bradley, P. A.; Flowers, R. A. II; Procter, D. J. J. Am. Chem. Soc. 2009, 131, 15467.

7. For 1,4-Sn shift from Si to C, see: Studer, A.; Amrein, S.; Matsubara, H.; Schiesser, C. H.; Doi, T.; Kawamura, T.; Fukuyama, T.; Ryu, I. Chem. Commun. 2003, 1190.

8. (a) Kim, S.; Lee, S.; Koh, J. S. J. Am. Chem. Soc. 1991, 113, 5106. (b) Kim, S.; Lim, K. M. Tetrahedron Lett. 1993, 34, 4851. For a theoretical study, see: (c) Kim, S.; Horvat, S. M.; Schiesser, C. H. Aust. J. Chem. 2002, 55, 753.

9. (a) Chang, S.-Y.; Shao, Y.-F.; Chu, S.-F.; Fan, G.-T.; Tsai, Y.-M. Org. Lett. 1999, 1, 945. (b) Ueng, S.-H.; Chen, M.-J.; Chu, S.-F.; Shao, Y.-F.; Fan, G.-T.; Chang, S.-Y.; Tsai, Y.-M. J. Org. Chem. 2006, 71,1502 . 